\title{
Successful application of extracorporeal membrane oxygenation due to pulmonary hemorrhage secondary to granulomatosis with polyangiitis
}

\author{
This article was published in the following Dove Press journal: \\ Drug Design, Development and Therapy \\ 23 July 2013 \\ Number of times this article has been viewed
}

\section{Wolfgang Hohenforst- \\ Schmidt ${ }^{\prime}$ \\ Arndt Petermann ${ }^{2}$ \\ Aikaterini Visouli ${ }^{3}$ \\ Paul Zarogoulidis ${ }^{4}$ \\ Kaid Darwiche ${ }^{5}$ \\ loanna Kougioumtzi ${ }^{6}$ \\ Kosmas Tsakiridis ${ }^{3}$ \\ Nikolaos Machairiotis ${ }^{6}$ \\ Markus Ketteler ${ }^{2}$ \\ Konstantinos Zarogoulidis ${ }^{4}$ \\ Johannes Brachmann' \\ 'Il Medical Clinic, Coburg Clinic, University of Wuerzburg, Coburg, Germany; ${ }^{2}$ Division of Nephrology, \\ Coburg Clinic, University of \\ Wuerzburg, Coburg, Germany; \\ ${ }^{3}$ Cardiothoracic Surgery Department, \\ "Saint Luke" Private Hospital, \\ Thessaloniki, Greece; "Pulmonary \\ Department, "G Papanikolaou" \\ General Hospital, Aristotle University \\ of Thessaloniki, Thessaloniki, Greece; \\ ${ }^{5}$ Department of Interventional \\ Pneumology, Ruhrlandklinik, West \\ German Lung Center, University \\ Hospital, University of Duisburg- \\ Essen, Essen, Germany; 'Surgery \\ Department (National Health \\ System), University General Hospital \\ of Alexandroupolis, Alexandroupolis, \\ Greece}

Correspondence: Paul Zarogoulidis

Pulmonary Department,

"G Papanikolaou" General Hospital,

Aristotle University of Thessaloniki,

Exohi II 00, Thessaloniki 57010, Greece

Tel +3023I 0992432

Fax +30 23। 0992433

Email pzarog@hotmail.com
Abstract: Extracorporeal membrane oxygenation (ECMO) is increasingly applied in adults with acute refractory respiratory failure that is deemed reversible. Bleeding is the most frequent complication during ECMO support. Severe pre-existing bleeding has been considered a contraindication to ECMO application. Nevertheless, there are cases of successful ECMO application in patients with multiple trauma and hemorrhagic shock or head trauma and intracranial hemorrhage. ECMO has proved to be life-saving in several cases of life-threatening respiratory failure associated with pulmonary hemorrhage of various causes, including granulomatosis with polyangiitis (Wegener's disease). We successfully applied ECMO in a 65-year-old woman with acute life-threatening respiratory failure due to diffuse massive pulmonary hemorrhage secondary to granulomatosis with polyangiitis, manifested as severe pulmonary-renal syndrome. ECMO sustained life and allowed disease control, together with plasmapheresis, cyclophosphamide, corticoids, and renal replacement therapy. The patient was successfully weaned from ECMO, extubated, and discharged home. She remains alive on dialysis at 17 months follow-up.

Keywords: ECMO, ARDS, polyangiitis, granulomatosis, hemorrhage

\section{Introduction}

Extracorporeal membrane oxygenation (ECMO) is used to preserve life in acute (de novo or decompensation of chronic) cardiac and/or respiratory failure, when optimal conventional therapy fails. Offering temporary support, veno-arterial ECMO is used in cardiac or cardiorespiratory failure, while veno-venous (VV) ECMO is used in respiratory failure without cardiac compromise. Respiratory ECMO is almost uniformly used as a bridge to recovery, thus it is indicated only when the respiratory failure is deemed reversible, while treatment of the underlying disease is essential. ${ }^{1-11}$

According to the Extracorporeal Life Support Organization (ELSO) ${ }^{12}$ General Guidelines, ECMO treatment is considered when the expected mortality with conventional treatment is higher than $50 \%$ and is usually indicated when it is higher than $80 \%$.

According to the 2004 ELSO Registry Report, ${ }^{1}$ ECMO had been mainly applied for neonatal respiratory failure (with $77 \%$ survival to discharge or transfer), while the adult respiratory group was the smallest group treated with ECMO, having a survival to discharge of 53\%. After the encouraging results of the randomized CESAR (Conventional ventilation or ECMO for Severe Adult Respiratory failure) trial ${ }^{2}$ and the ECMO treatment for acute respiratory failure associated with the influenza A H1N1 
viral infection, ECMO application for adult respiratory failure has been tremendously increased. ${ }^{9}$ According to the ELSO $^{12}$ International Summary (January 2013), the adult respiratory ECMO cases outnumber the adult cardiac cases and have a survival to discharge or transfer of 55\%. In our hospital the ratio of adult respiratory versus adult cardiac cases is $10: 1$.

Wegener's granulomatosis (WG), renamed "granulomatosis with polyangiitis" (GPA), is an antineutrophil cytoplasmic autoantibody (ANCA)-associated vasculitis, characterized by multifocal vascular necrotizing inflammation and granulomas. Genetic and microbial factors may play a role in induction and expression of the autoimmune process. GPA is a multisystem disease that can affect any organ/system, having a variable clinical presentation. Nevertheless, it is most frequently manifested as small vessel vasculitis affecting the upper and lower respiratory tract and the kidneys. In ANCA-associated vasculitis, including GPA, alveolar hemorrhage, and concomitant glomerulonephritis causing renal insufficiency (pulmonary-renal syndrome) are associated with high mortality. , $^{5-11,13-22}$

\section{Case report}

A 65-year-old woman was transferred from an associated hospital (after 2 days of hospitalization) with acute renal and respiratory failure after repeated episodes of hemoptysis.

She had been treated for chronic sinusitis the year before, had history of gross hematuria for 16 days, and repeated hemoptysis the 2 days before admission to our hospital. Lesions characteristic of GPA were found on nasal endoscopy, fresh blood originating from all segmental orifices was revealed on two bronchoscopies. Massive bilateral pulmonary opacities, consolidations attributed to alveolar infiltrations, and a few small cavitary lesions were revealed on computed tomography, which were performed at the referring hospital (Figure 1A, B, and Figure 2). Therefore the first prednisolone pulse of $500 \mathrm{mg}$ intravenous (IV) was given in the referring hospital.

The gross hematuria was followed by severe oliguria and periods of anuria. Numerous erythrocytes containing approximately $20 \%$ acanthocytes were revealed in the urinary sediment, as well as red blood cell casts. The creatinine rapidly increased in the 48 hours after the first episode of hemoptysis, being $5.9 \mathrm{mg} / \mathrm{dL}$ on admission to our hospital. The diagnosis of rapidly progressive glomerulonephritis was made based on clinical observations.

Her respiratory function continued to deteriorate. She became progressively dyspneic, and after the first night on referral, became tachypneic. Furthermore, she was severely
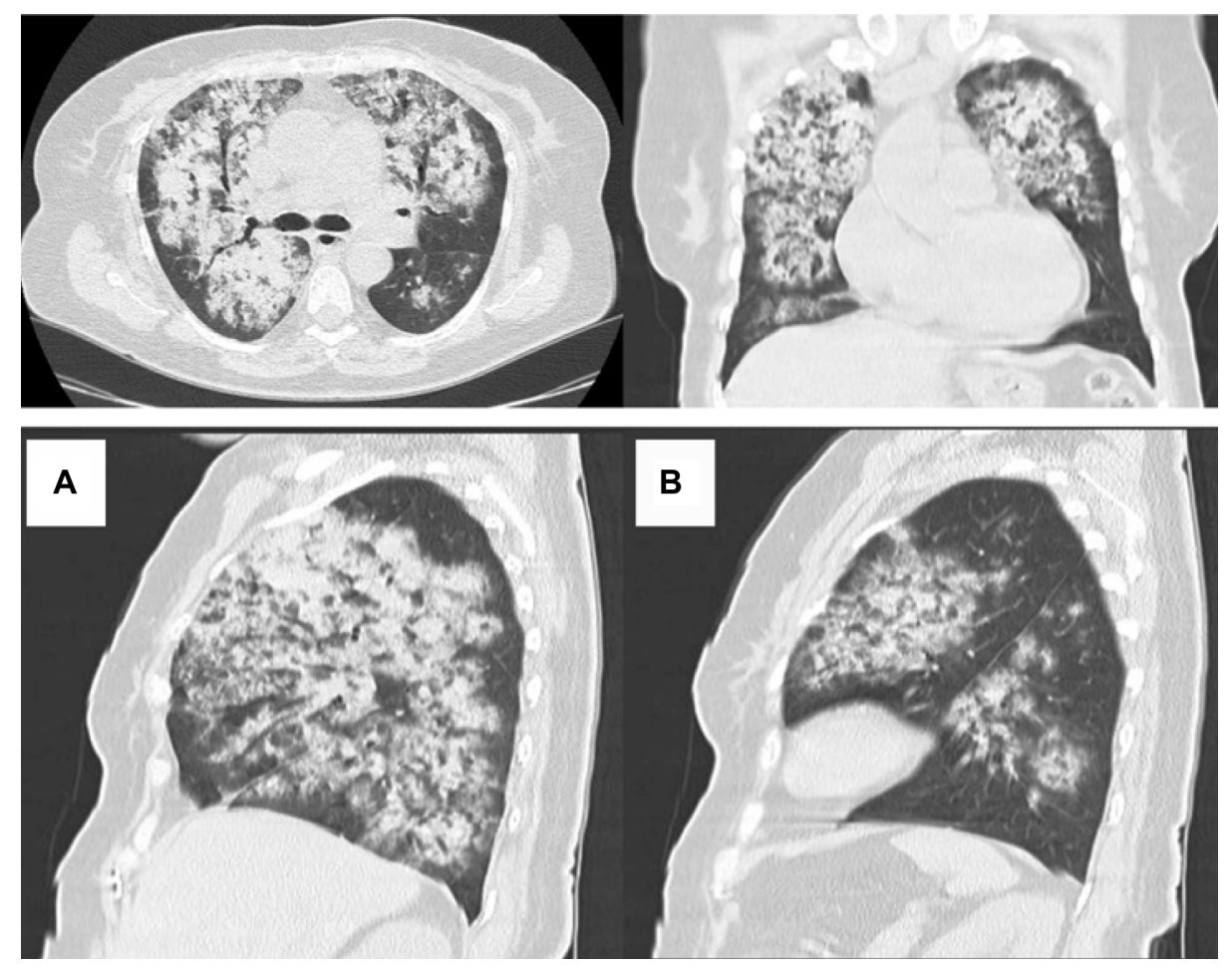

Figure I Chest computed tomography on admission showing bilateral opacities attributed to alveolar infiltrations as well as a few small cavitary lesions. (A) left lung, (B) right lung. 


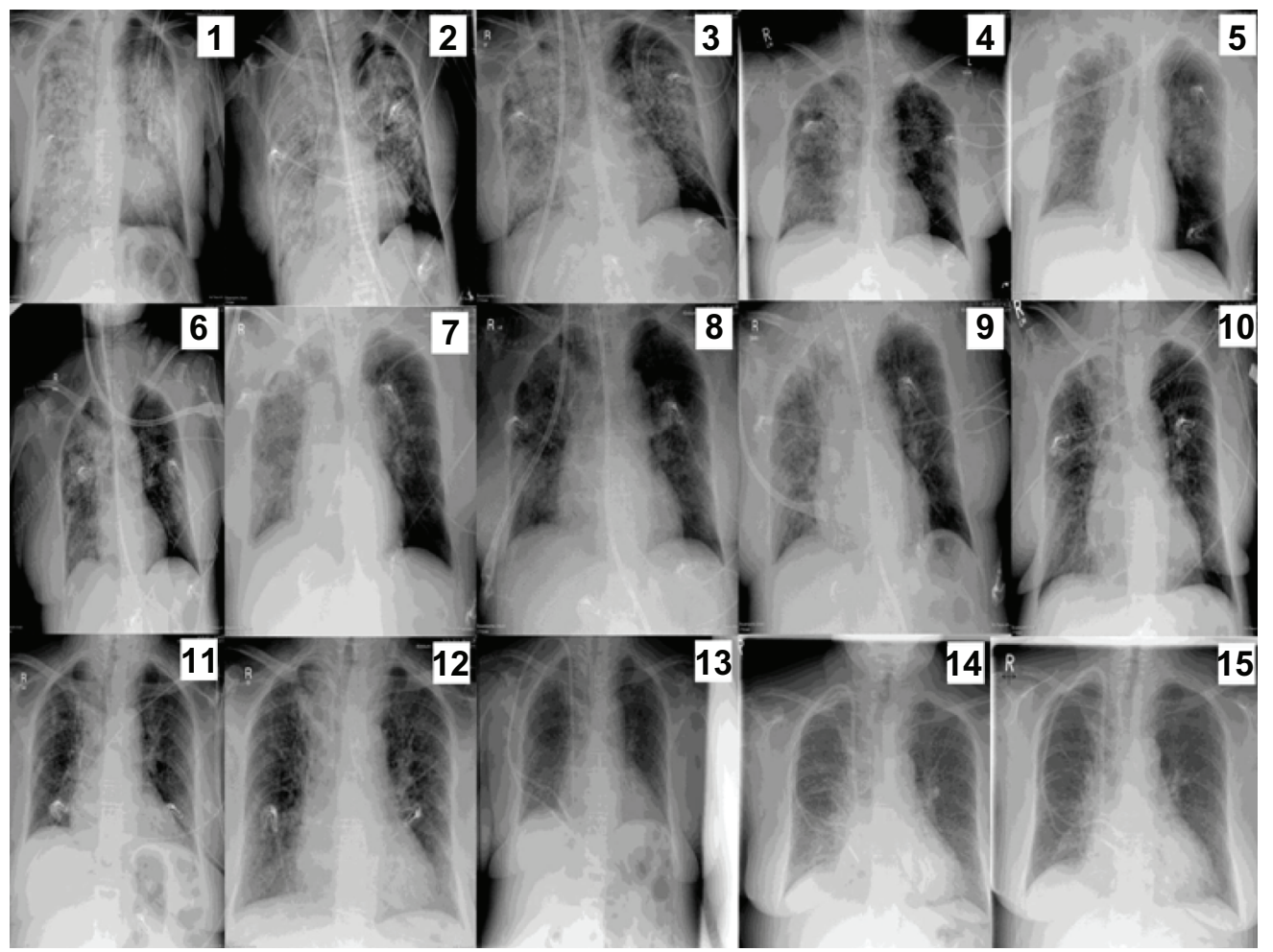

Figure 2 Sequential dates of radiographic presentation.

Notes: (I) September 9, 20 I I, (2) September 10, 20 I , (3) September II, 20I I, (4) September I3, 20 I I, (5) September I4, 20 I I, (6) September I5, 20 I I, (7) September I6, 20 I I, (8) September 17, 20 I I, (9) September 19, 20 I I, ( I 0) September 23, 20 I I, (I I) September 24, 20 I I, ( I 2) September 26, 20 I I, ( I 3) September 30, 20 I I, ( I 4) October 7, 20II, (15) October 10, 20II.

desaturated $\left(\mathrm{PaO}_{2} 49 \mathrm{mmHg}\right)$, and was fitted with a face mask with 10 liters of oxygen per minute. She had up to 30 episodes of hemoptysis daily for 3 consecutive days. She was semielectively intubated the day after her admission.

The first 3 hours after intubation, $200 \mathrm{~mL} /$ hour of blood was suctioned from the endotracheal tube. On repeated bronchoscopies, there was continued massive diffuse bleeding, originating from all segmental orifices (more prominent on the right side). The ventilator settings had to be elevated (biphasic positive airway pressure) from $28 / 10 \mathrm{~cm} \mathrm{H}_{2} \mathrm{O}$ to $35 / 15 \mathrm{~cm} \mathrm{H}_{2} \mathrm{O}$, with steadily reduced inspiratory to expiratory ratio, resulting in ratios near to $1: 1$. Fractional inspired oxygen was increased from $60 \%$ to $100 \%$, but hypoxemia persisted $\left(\mathrm{PaO}_{2} 52.4 \mathrm{mmHg}\right.$ before ECMO initiation). Continued hemoptysis resulted not only in reduced alveolar diffusion capacity but also in repeated airway obstruction. Despite severe respiratory compromise, she remained hemodynamically stable, with good ventricular function on echocardiography, and without requirement of inotropes and/or vasoconstrictors. Twelve hours after intubation, her Horowitz-index was 50, and a VV-ECMO by the Cardiohelp System of Maquet (MAQUET Cardiopulmonary AG, Hirrlingen, Germany), including the HLS Set Advanced 5.0 (MAQUET Cardiopulmonary AG,
Hirrlingen, Germany) for application of a maximal flow of $5 \mathrm{~L} /$ minute, was semi-electively inserted percutaneously, with inflow cannula to right femoral vein (21 catheter) and outflow cannula to the right internal jugular vein (19 catheter). The ECMO flow was initially set to $4 \mathrm{~L} /$ minute, biphasic positive airway pressure and fractional inspired oxygen levels were drastically decreased, while blood gases were dramatically improved (Table 1). Because of high ANCA levels (proteinase 3-ANCA $150 \mathrm{U} / \mathrm{mL}$; normal lab range $<4 \mathrm{U} / \mathrm{mL}$ ), the presence of acanthocytosis with red blood cell casts, together with acute renal failure and diffuse hemorrhagic alveolar infiltrates, the diagnosis of GPA presenting as pulmonary-renal syndrome was made. Additionally, both anti-double-stranded DNA antibodies and anti-glomerular-basement antibodies were negative, making both lupus erythematodes and Goodpasture's syndrome improbable.

Immunosuppression with prednisolone (500 mg IV daily) that had been started at the referring hospital was continued and supported by plasmapheresis to reduce the level of ANCAautoantibodies after inserting a Shaldon catheter into the left jugular vein 9 hours before ECMO initiation. Because of anuria and fluid overload, continuous VV hemofiltration through the Shaldon catheter was started during the first 24 hours of ECMO 


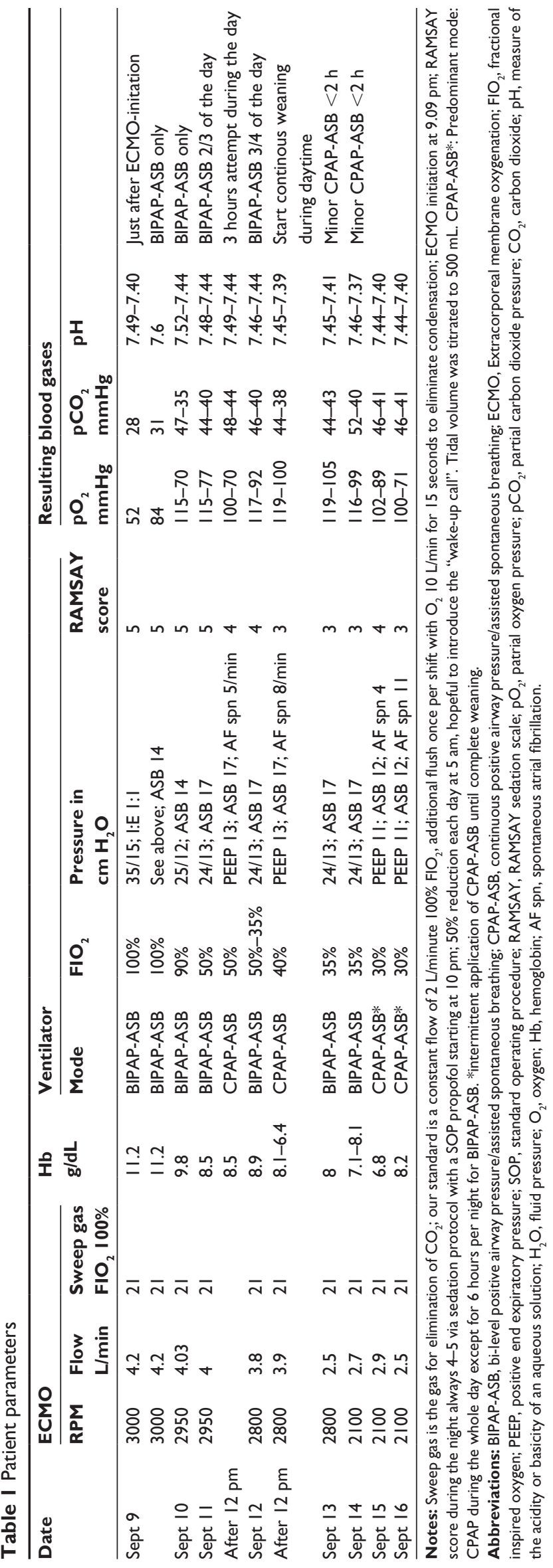

support in order to replace the missing kidney function. As cyclophosphamide is removed by hemofiltration pulse, cyclophosphamide was delayed until day 2 , following the second plasmapheresis and the second hemofiltration.

To reduce the risk of bleeding, citrate was used as anticoagulation regimen for plasmapheresis, which enabled an intracorporeal activated clotting time (ACT) of 160-200, without changes in systemic coagulation. For the same reasons, citrate hemofiltration with neutralization of systemic citrate by calcium perfusion was used for the first and second hemofiltration. Later, heparin was used for the following two hemofiltrations, but due to suspected heparin-induced thrombocytopenia type II, argatroban was adapted thereafter with a targeted ACT range between 160-200. The length of hemofiltration was limited to approximately 5 to 6 hours to reduce the risk of bleeding. No anticoagulation was administered during ECMO, except the registered ACT fluctuated between 160-200 and activated partial thromboplastin time (aPTT) between 41-66 seconds. The platelet count fluctuated between 38,000-245,000 uL. Platelets were transfused with counts decreasing below 50,000 uL during ECMO (Table 2).

Hemoptysis progressively decreased and stopped 6 days after ECMO initiation. Clinical, radiological, bronchoscopical, and laboratory findings showed progressive improvement that allowed ECMO weaning and discontinuation after 10 days of support, and extubation on the following day, after 11 days of mechanical ventilation. The weaning process is described in (Table 1).

Continuous VV hemofiltration was continued daily for 20 days, and replaced by hemodialysis three times a week due to terminal renal failure. Plasmapheresis was performed daily for 15 days (with administration of 31 units of fresh frozen plasma) and continued every second day for 21 more days (with administration of human albumin $4.2 \%$ ), effectively reducing the proteinase 3 titers.

The patient made a remarkable recovery, maintained good respiratory function, and was discharged home after 46 days of hospitalization and chronic dialysis.

Pulse cyclophosphamide was administered for a total of 3 months, up to a total dose of $4.73 \mathrm{gm}$, followed by azathioprine (100 mg orally, daily) and prednisolone (tapered to $5 \mathrm{mg}$ orally daily). At 17 month follow-up, she had no relapses maintaining good respiratory function.

\section{Discussion}

ECMO requires systemic anticoagulation with continuous heparin infusion to maintain an ACT of about 1.5 times that of normal. Bleeding is the most common complication during 
Table 2 Citrate hemofiltration was started to reduce the risk of systemic anticoagulation

\begin{tabular}{|c|c|c|c|c|c|c|c|c|c|}
\hline Day & I & 2 & 3 & 4 & 5 & 6 & 7 & 8 & $\rightarrow$ \\
\hline Plasmaseparation & Citrate & Citrate & Citrate & Citrate & Citrate & Citrate & Citrate & Citrate & $\rightarrow$ \\
\hline \multirow[t]{3}{*}{ Hemofiltration } & Citrate & Citrate & & Heparin & Heparin & Argatroban & Argatroban & Argatroban & $\rightarrow$ \\
\hline & & & & $\uparrow$ & & $\uparrow$ & & & \\
\hline & & & & $\begin{array}{l}\text { Decrease of } \\
\text { hemoptysis }\end{array}$ & & Thrombocytopenia & & & \\
\hline
\end{tabular}

Notes: Decreasing hemoptysis enabled a change to heparin on day 4. Because of developing thrombocytopenia hemofiltration was continued on argatroban. Plasmapheresis was administered with citrate as standard in our department. $\uparrow$, increased; $\rightarrow$, ongoing treatment.

ECMO support, attributed to anticoagulation and thrombocytopathia that are accelerated by the oxygenator-related blood trauma. The risk of systemic bleeding with anticoagulation is a relative contraindication to ECMO. ${ }^{3,5,9,11,12,23}$ Furthermore, preexisting severe bleeding has been considered a contraindication..$^{5,924,25}$ Nevertheless, good results have been reported in ECMO recipients with severe respiratory failure associated with trauma and hemorrhagic shock, ${ }^{24}$ intracranial bleeding, ${ }^{25}$ and severe pulmonary bleeding of various causes. ${ }^{4-11,17-22}$

In 1994, Siden et al reported ECMO application in four cases of acute, severe pulmonary hemorrhage in infancy. ${ }^{26}$ Kolovos et al, ${ }^{4}$ in 2002, reported $100 \%$ survival with VV or vino-arterial ECMO in a case series of nine children with severe acute respiratory failure caused by pulmonary hemorrhage secondary to sepsis or autoimmune diseases including GPA. Reviewing the ELSO database they reported $72 \%$ and $67 \%$ survival among 18 neonates and three children, respectively, who received ECMO for the treatment of pulmonary hemorrhage. Subsequently, ECMO has been successfully applied to children with severe respiratory failure due to pulmonary hemorrhage secondary to idiopathic pulmonary hemosiderosis, ${ }^{27}$ fulminant Wilson disease, ${ }^{28}$ nodose polyarteritis, ${ }^{29}$ Goodpasture's syndrome, ${ }^{6}$ and ANCA-related vasculitis, including severe microscopic polyangiitis, ${ }^{5,8}$ and GPA. ${ }^{7,9}$

ECMO has been successfully applied to adults with respiratory failure due to pulmonary hemorrhage attributed to various causes, including autoimmune vasculitis. There are case reports of successful ECMO application to adults with refractory life-threatening respiratory failure due to warfarin-exacerbated diffuse alveolar hemorrhage, ${ }^{30}$ massive pulmonary hemorrhage after lobar lung transplantation, ${ }^{31}$ massive lung bleeding with airway blood clot obstruction after pulmonary endarterectomy, ${ }^{32,33}$ pulmonary hemorrhage related with right middle lobe bronchiectasis, ${ }^{34}$ and diffuse alveolar hemorrhage after silicone embolism..$^{35}$

There are several case reports of ECMO application in adult patients with refractory acute respiratory failure associated with severe pulmonary bleeding secondary to autoimmune vasculitis, including ANCA-associated vasculitis. Initial improvement and weaning from ECMO has been reported in an adult patient with Goodpasture's-like pulmonary-renal syndrome, who subsequently died after rebleeding. ${ }^{36}$ There are at least seven case reports of $\mathrm{VV}$ ECMO applied to adults with acute refractory respiratory failure secondary to Wegener's granulomatosis, most of which had severe preexisting pulmonary hemorrhage. ${ }^{11,18-22,37}$

Measures to normalize the coagulation status applied in ECMO recipients treated for pulmonary bleeding include reduced heparin administration, transfusions of platelets, fresh frozen plasma, and specific clotting factors according to deficiencies, and administration of $\varepsilon$-aminocaproic acid in fibrinolysis. ${ }^{3,5,9,12,23}$ Nafamostat mesylate as anticoagulant is also rarely reported. ${ }^{31,36}$ Heparin infusion to maintain an ACT of $160-180^{4,5}$ or $130-150$ seconds (instead of the institutional standard of 180-220) and a modified ECMO circuit with two oxygenators placed in parallel (one primed in-line to allow quick change in case of clotting $)^{9}$ have been reported in pediatric patients with pulmonary hemorrhage due to GPA.

Thrombo-resistant coated circuits (heparin-bonded, nitric oxide-treated $)^{4}$ may allow withholding heparin for a period of time with less risk of clotting, particularly if flow is kept high. Initially, heparin-free or prolonged heparin-free ECMO has been applied in multiple trauma and intracranial bleeding patients, respectively. ${ }^{24,25}$ Heparin administration after the first 48 hours, ${ }^{11,21}$ initial heparin anticoagulation, and later conversion to lepirudin after complication by heparin induced thrombocytopenia ${ }^{20}$ have been reported in adult patients with pulmonary hemorrhage due to GPA.

ECMO proved life-saving in our patient. It maintained oxygenation necessary due to massive pulmonary hemorrhage obstruction and alveolar diffusion problems with less ventilator induced trauma, and it supported the patient until resolution of her respiratory failure, providing time for treatment and control of the underlying disease by plasmapheresis and immunosuppression. Thrombo-resistant circuits were used, and regional anticoagulation was 
administered to plasmapheresis. Systemic anticoagulation for hemofiltration was reduced to a minimum by either using citrate hemofiltration or by time restriction using heparin or argatroban with ranges of ACT between 160-200 and aPTT between 41-66 seconds. Pulmonary bleeding stopped completely within 6 days of ECMO support. There was minor extrapulmonary bleeding (eg, nose, insertion points of catheters) until day 8 after ECMO initiation and no clotting complications.

ECMO application in adult respiratory failure has been questioned $;{ }^{38}$ nevertheless, it is gaining an increasing role, ${ }^{39}$ and most contraindications to its use are becoming weaker. Respiratory ECMO is applied as a rescue therapy offering respiratory support to maintain life, as a bridge to recovery in reducing the ventilator-induced lung injury (oxygen toxicity and barotrauma) and allowing pulmonary rest, ${ }^{4,9}$ as a supportive therapy providing time for diagnosis and treatment of the underlying causative disease until its control or resolution, and rarely as a bridge to lung transplantation. ${ }^{40,41}$ ECMO treatment in respiratory failure associated with severe pulmonary bleeding imposes a management dilemma. Although limited, the reported experience of successful ECMO application in acute respiratory failure associated with pulmonary bleeding continues to accumulate, ${ }^{4-11,17-22,26-37}$ thus encouraging consideration of its application. ${ }^{39}$

\section{Disclosure}

The authors report no conflicts of interest in this work.

\section{References}

1. Conrad SA, Rycus PT, Dalton H. Extracorporeal life support registry report 2004. ASAIO J. 2005;51(1):4-10.

2. Peek GJ, Mugford M, Tiruvoipati R, et al; CESAR trial collaboration. Efficacy and economic assessment of conventional ventilatory support versus extracorporeal membrane oxygenation for severe adult respiratory failure (CESAR): a multicentre randomised controlled trial. Lancet. 2009;374(9698):1351-1363.

3. Pitsis AA, Visouli AN. Mechanical assistance of the circulation during cardiogenic shock. Curr Opin Crit Care. 2011;17(5):425-438.

4. Kolovos NS, Schuerer DJ, Moler FW, et al. Extracorporeal life support for pulmonary hemorrhage in children: a case series. Crit Care Med. 2002;30(3):577-580.

5. Agarwal HS, Taylor MB, Grzeszczak MJ, et al. Extracorporeal membrane oxygenation and plasmapheresis for pulmonary hemorrhage in microscopic polyangiitis. Pediatr Nephrol. 2005;20(4): 526-528.

6. Dalabih A, Pietsch J, Jabs K, Hardison D, Bridges BC. Extracorporeal membrane oxygenation as a platform for recovery: a case report of a child with pulmonary hemorrhage, refractory hypoxemic respiratory failure, and new onset goodpasture syndrome. J Extra Corpor Technol. 2012;44(2):75-77.

7. Hernandez ME, Lovrekovic G, Schears G, et al. Acute onset of Wegener's granulomatosis and diffuse alveolar hemorrhage treated successfully by extracorporeal membrane oxygenation. Pediatr Crit Care Med. 2002;3(1):63-66.
8. Di Maria MV, Hollister R, Kaufman J. Case report: severe microscopic polyangiitis successfully treated with extracorporeal membrane oxygenation and immunosuppression in a pediatric patient. Curr Opin Pediatr. 2008;20(6):740-742.

9. Joseph M, Charles AG. Early extracorporeal life support as rescue for Wegener granulomatosis with diffuse alveolar hemorrhage and acute respiratory distress syndrome: a case report and literature review. Pediatr Emerg Care. 2011;27(12):1163-1166.

10. Guo Z, Li X, Jiang LY, Xu LF. Extracorporeal membrane oxygenation for the management of respiratory failure caused by diffuse alveolar hemorrhage. J Extra Corpor Technol. 2009;41(1):37-40.

11. Ahmed SH, Aziz T, Cochran J, Highland K. Use of extracorporeal membrane oxygenation in a patient with diffuse alveolar hemorrhage. Chest. 2004;126(1):305-309.

12. Extracorporeal Life Support Organization. ELSO Guidelines for Cardiopulmonary Extracorporeal Life Support. Ann Arbor, MI; 2009. Available from: http://www.elso.med.umich.edu/WordForms/ELSO $\% 20$ Guidelines\%20General\%20A11\%20ECLS\%20Version1.1.pdf.

13. Falk RJ, Gross WL, Guillevin L, et al. Granulomatosis with polyangiitis (Wegener's): an alternative name for Wegener's granulomatosis. Arthritis Rheum. 2011;63(4):863-864.

14. Jennette JC. Nomenclature and classification of vasculitis: lessons learned from granulomatosis with polyangiitis (Wegener's granulomatosis). Clin Exp Immunol. 2011;164(Suppl 1):7-10.

15. Chung SA, Xie G, Roshandel D, et al. Meta-analysis of genetic polymorphisms in granulomatosis with polyangiitis (Wegener's) reveals shared susceptibility loci with rheumatoid arthritis. Arthritis Rheum. 2012;64(10):3463-3471.

16. Kallenberg CG. Pathogenesis of ANCA-associated vasculitides. Ann Rheum Dis. 2011;70(Suppl 1):i59-i63.

17. Matsumoto T, Ueki K, Tamura S, et al. Extracorporeal membrane oxygenation for the management of respiratory failure due to ANCAassociated vasculitis. Scand J Rheumatol. 2000;29(3):195-197.

18. Hartman A, Nordal K, Svennevig J, et al. Successful use of artificial lung (ECMO) and kidney in the treatment of a 20 year-old female with Wegener's syndrome. Nephrol Dial Transplant. 1994;9(3):316-319.

19. Rosengarten A, Elmore P, Epstein J. Long distance road transport of a patient with Wegener's Granulomatosis and respiratory failure using extracorporeal membrane oxygenation. Emerg Med (Fremantle). 2002;14(2):181-187.

20. Balasubramanian SK, Tiruvoipati R, Chatterjee S, Sosnowski A, Firmin RK. Extracorporeal membrane oxygenation with lepirudin anticoagulation for Wegener's granulomatosis with heparin-induced thrombocytopenia. ASAIO J. 2005;51(4):477-479.

21. Gay SE, Ankney N, Cochran JB, Highland KB. Critical care challenges in the adult ECMO patient. Dimens Crit Care Nurs. 2005;24(4):157-162; quiz 163-164.

22. Barnes SL, Naughton M, Douglass J, Murphy D. Extracorporeal membrane oxygenation with plasma exchange in a patient with alveolar haemorrhage secondary to Wegener's granulomatosis. Intern Med J. 2012;42(3):341-342.

23. Pitsis AA, Visouli AN. Update on ventricular assist device management in the ICU. Curr Opin Crit Care. 2008;14(5):569-578.

24. Arlt M, Philipp A, Voelkel S, et al. Extracorporeal membrane oxygenation in severe trauma patients with bleeding shock. Resuscitation. 2010;81(7):804-809.

25. Muellenbach RM, Kredel M, Kunze E, et al. Prolonged heparin-free extracorporeal membrane oxygenation in multiple injured acute respiratory distress syndrome patients with traumatic brain injury. J Trauma Acute Care Surg. 2012;72(5):1444-1447.

26. Siden HB, Sanders GM, Moler FW. A report of four cases of acute, severe pulmonary hemorrhage in infancy and support with extracorporeal membrane oxygenation. Pediatr Pulmonol. 1994;18(5):337-341.

27. Sun LC, Tseng YR, Huang SC, et al. Extracorporeal membrane oxygenation to rescue profound pulmonary hemorrhage due to idiopathic pulmonary hemosiderosis in a child. Pediatr Pulmonol. 2006;41(9):900-903. 
28. Son SK, Oh SH, Kim KM, et al. Successful liver transplantation following veno-arterial extracorporeal membrane oxygenation in a child with fulminant Wilson disease and severe pulmonary hemorrhage: a case report. Pediatr Transplant. 2012;16(7):E281-E285.

29. Keller R, Torres S, Iölster T, et al. Extracorporeal membrane oxygenation and plasmapheresis in the treatment of severe pulmonary hemorrhage secondary to nodose polyarteritis. Arch Argent Pediatr. 2012;110(4):e80-e85. Spanish.

30. Lee JH, Kim SW. Successful management of warfarin-exacerbated diffuse alveolar hemorrhage using an extracorporeal membrane oxygenation. Multidiscip Respir Med. 2013;8(1):16.

31. Kotani K, Ichiba S, Andou M, et al. Extracorporeal membrane oxygenation with nafamostat mesilate as an anticoagulant for massive pulmonary hemorrhage after living-donor lobar lung transplantation. J Thorac Cardiovasc Surg. 2002;124(3):626-627.

32. Kolníková I, Kunstýř J, Lindner J, et al. Extracorporeal membrane oxygenation used in a massive lung bleeding following pulmonary endarterectomy. Prague Med Rep. 2012;113(4):299-302.

33. Y1ldızeli B, Arslan O, Taş S, et al. Management of massive pulmonary hemorrhage following pulmonary endarterectomy. Thorac Cardiovasc Surg. 2012.
34. Grimme I, Winter R, Kluge S, Petzoldt M. Hypoxic cardiac arrest in pregnancy due to pulmonary hemorrhage. BMJ Case Rep. 2012; 2012.

35. Mongero LB, Brodie D, Cunningham J, et al. Extracorporeal membrane oxygenation for diffuse alveolar hemorrhage and severe hypoxemic respiratory failure from silicone embolism. Perfusion. 2010;25(4):249-252; discussion 253-254.

36. Daimon S, Umeda T, Michishita I, Wakasugi H, Genda A, Koni I. Goodpasture's-like syndrome and effect of extracorporeal membrane oxygenator support. Intern Med. 1994;33(9):569-573.

37. Loscar M, Hummel T, Haller M, et al. ARDS and Wegener granulomatosis. Anaesthesist. 1997;46(11):969-973. German.

38. Kirby RR, Lobato EB. Extracorporeal membrane oxygenation and pulmonary disease. Chest. 2005;127(1):413.

39. Weber TR. Extending the uses of ECMO. Chest. 2004;126(1):9-10.

40. Bermudez CA, Rocha RV, Zaldonis D, et al. Extracorporeal membrane oxygenation as a bridge to lung transplant: midterm outcomes. Ann Thorac Surg. 2011;92(4):1226-1231; discussion 1231-1232.

41. Toyoda Y, Bhama JK, Shigemura N, et al. Efficacy of extracorporeal membrane oxygenation as a bridge to lung transplantation. J Thorac Cardiovasc Surg. 2013;145(4):1065-1070; discussion 1070-1071.

\section{Publish your work in this journal}

Drug Design, Development and Therapy is an international, peerreviewed open-access journal that spans the spectrum of drug design and development through to clinical applications. Clinical outcomes, patient safety, and programs for the development and effective, safe, and sustained use of medicines are a feature of the journal, which

\section{Dovepress}

has also been accepted for indexing on PubMed Central. The manuscript management system is completely online and includes a very quick and fair peer-review system, which is all easy to use. Visit http://www.dovepress.com/testimonials.php to read real quotes from published authors.

Submit your manuscript here: http://www.dovepress.com/drug-design-development-and-therapy-journal 